\title{
Nociceptor Hyper-Responsiveness during Vincristine-Induced Painful Peripheral Neuropathy in the Rat
}

\author{
Kimberly D. Tanner, David B. Reichling, and Jon D. Levine \\ Departments of Medicine, Anatomy, and Oral and Maxillofacial Surgery, Division of Rheumatology, and Program in \\ Neuroscience, University of California, San Francisco, California $94143-0452$
}

\begin{abstract}
Neuropathic pain accompanies peripheral nerve injury after a wide variety of insults including metabolic disorders, traumatic nerve injury, and neurotoxic drugs. Chemotherapy-induced neuropathic pain, caused by drugs such as vincristine and taxol, occurs in cancer patients who receive these drugs as antineoplastic agents. Although a variety of remediations have been attempted, the absence of knowledge concerning mechanisms of chemotherapy-induced neuropathic pain has hindered the development of treatment strategies. Vincristine, a widely used chemotherapeutic agent, produces painful peripheral neuropathy in humans and mechanical hyperalgesia in rats. To test the hypothesis that alterations in C-fiber nociceptor function occur during vincristine-induced painful peripheral neuropathy, we performed in vivo extracellular recordings of single neurons from the saphenous nerve of vincristine-treated rats. Forty-one percent of $\mathrm{C}$-fiber nociceptors were significantly hyper-responsive to suprathreshold mechanical stimulation. As a population, these mechanically hyper-responsive nociceptors also had significantly greater responses to suprathreshold heat
\end{abstract}

Chemotherapy-induced pain is a form of neuropathic pain caused by neurotoxic drugs such as vincristine and taxol and is characterized by painful paresthesias and dysesthesias. The vinca alkaloid vincristine is a widely used antineoplastic agent that is administered alone or in combination with other drugs in the treatment of many tumor types (Weiss et al., 1974; Kaplan and Wiernik, 1982). Vincristine is thought to exert its antineoplastic effects by binding to tubulin in mitotically active cells, disrupting microtubule formation in mitotic spindles, and thus preventing cell division (Olmsted and Borisy, 1973; Himes et al., 1976; Owellen et al., 1976). The clinical antineoplastic efficacy of vincristine is limited by the development of a dose-dependent sensorimotor neuropathy (Sandler et al., 1969; Holland et al., 1973). This sensorimotor neuropathy seems to occur in two major stages (Weiss et al., 1974; Kaplan and Wiernik, 1982; McCarthy and Skillings, 1992). In the early stage, peripheral axons are damaged by vincristine, and the principal symptoms are paresthesias and dysesthesias. In the later stage, which occurs more frequently at

Received Feb. 18, 1998; revised May 21, 1998; accepted May 28, 1998.

This research was supported by National Institutes of Health Grant NS21647 and by the American Cancer Society. K.D.T. was supported by a National Science Foundation predoctoral fellowship and an American Heart Association predoctoral fellowship. We thank Drs. Michael Gold, Paul Green, and Henry Mahncke for many helpful discussions during the course of these studies and for comments on this manuscript.

Correspondence should be addressed to Dr. Jon D. Levine, National Institutes of Health Pain Center, C-522, Box 0440, University of California, San Francisco, CA 94143-0440.

Copyright (C) 1998 Society for Neuroscience $0270-6474 / 98 / 186480-12 \$ 05.00 / 0$ stimulation; however, heat hyper-responsiveness was found only in a subset of these nociceptors and was never detected in the absence of mechanical hyper-responsiveness. In addition, mean conduction velocities of $\mathrm{A}$-fibers and $\mathrm{C}$-fibers in vincristine-treated rats were significantly slowed. Mean heat and mechanical activation thresholds of C-fiber nociceptors, their distribution among subclasses, and the percentage of spontaneously active neurons in vincristine-treated rats were not statistically different from controls. Vincristine does not, therefore, cause generalized impairment of $\mathrm{C}$-fiber nociceptor function but rather specifically interferes with mechanisms underlying responsiveness to suprathreshold stimuli. Furthermore, vincristine-induced nociceptor hyper-responsiveness may involve alterations specifically in mechanotransduction in some nociceptors and alterations in general cellular adaptation mechanisms in others.

Key words: C-fiber; primary afferent nociceptor; neuropathic pain; peripheral neuropathy; vincristine; mechanotransduction

higher doses, axons are lost, and the principal finding is loss of motor function.

Recently, we established an animal model of vincristineinduced painf ul neuropathy in the rat (Aley et al., 1996). Systemic administration of vincristine $(100 \mu \mathrm{g} / \mathrm{kg})$, administered intravenously over a 2 week period, produced mechanical hyperalgesia that developed during the second week of vincristine administration and persisted for more than a week after the final injection of vincristine. The hyperalgesia was dose-dependent and occurred at doses of vincristine similar to those administered clinically to achieve antineoplastic efficacy (McLeod and Penny, 1969; Sandler et al., 1969; Casey et al., 1973; Holland et al., 1973). Higher doses of vincristine also cause loss of motor function in the rat (Aley et al., 1996), similar to the later stage of neuropathy in humans. Preliminary anatomical evidence suggests that there is damage to unmyelinated sensory axons before there are any signs of axonal loss in this rat model (Tanner et al., 1998). Therefore, we propose that vincristine-induced hyperalgesia in the rat is a model of the early stage of vincristine-induced chemotherapeutic neuropathy.

Several lines of evidence suggest that alterations in peripheral nerve function contribute to the sensory alterations in vincristine-induced painful peripheral neuropathy. For example, systemically administered vincristine does not cross the bloodbrain barrier to a significant extent (Castle et al., 1976; Greig et al., 1990; Zhou et al., 1990). It has been hypothesized that peripheral neurons are highly sensitive to vincristine because nerve terminal function is dependent on intact axonal transport 

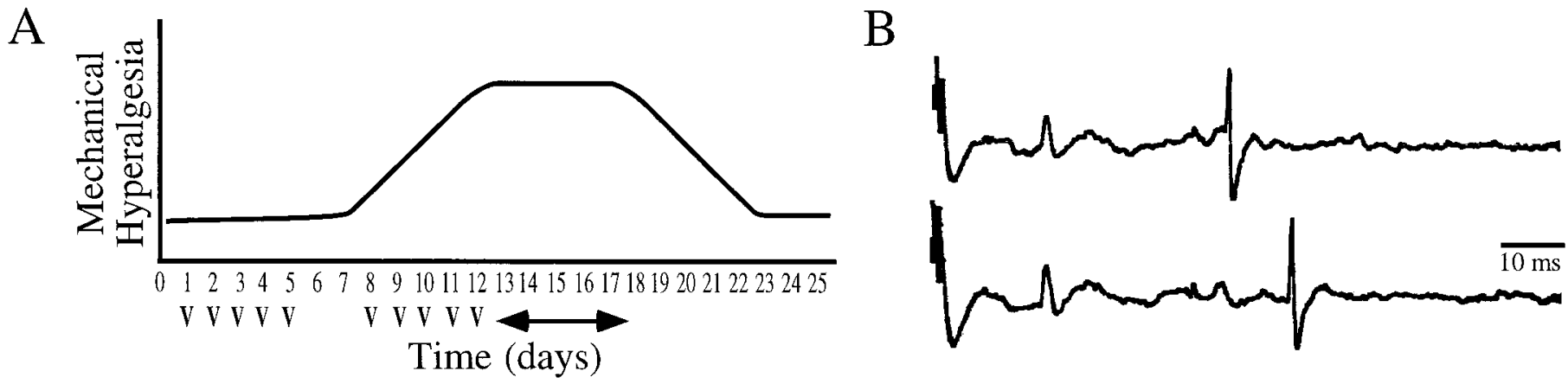

Figure 1. Experimental paradigm. $A$, Schematic of the experimental timeline. Rats were injected intravenously with vincristine sulfate $(V)$ at $100 \mu \mathrm{g} / \mathrm{kg}$ on days 1-5 and 8-12. The arrow shows the period during which electrophysiological recordings were made from sensory fibers in the saphenous nerves of vincristine-treated rats. Data from the 5 recording days were pooled. $B$, The requirement that each $C$-fiber studied show a slowed conduction velocity in response to electrical stimulation after mechanical stimulation of the receptive field. This "collision test" established that the mechanical receptive field under study was innervated by the C-fiber whose latency to electrical stimulation was shifted. Top, The activation of a C-fiber with a latency of 46 msec in response to electrical stimulation of the whole nerve. Bottom, Electrical activation of the same C-fiber, at this time with a latency of 56 msec, after mechanical stimulation of its receptive field. This C-fiber had a conduction velocity of $0.70 \mathrm{~m} / \mathrm{sec}$ and a mechanical threshold of $1.7 \mathrm{gm}$. Note that another fiber conducted at 16 msec both before and after the collision test.

and maintenance of the peripheral terminal via extremely long axons (Shelanski and Wisniewski, 1969). Interestingly, the paresthesias and dysesthesias reported in humans are most pronounced in the distal extremities (Sandler et al., 1969; Holland et al., 1973), namely, those areas innervated by the longest sensory neurons.

To test the hypothesis that increased sensitivity and responsiveness of C-fiber nociceptors occur during vincristine-induced hyperalgesia, we used in vivo single-unit electrophysiological techniques to examine peripheral sensory neurons in vincristinetreated rats.

\section{MATERIALS AND METHODS}

\section{Animals}

Experiments were performed on 200-400 gm male Sprague Dawley rats (Bantin-Kingman, Fremont, CA). Rats were housed in a temperatureand humidity-controlled environment and were maintained on a $12 \mathrm{hr}$ light/dark cycle. Food and water were available ad libitum. Experiments were approved by the Committee on Animal Research at the University of California, San Francisco.

\section{Vincristine treatment}

Vincristine sulfate (Sigma, St. Louis, MO) was dissolved in saline to a stock concentration of $1 \mathrm{mg} / \mathrm{ml}$, with a $\mathrm{pH}$ between 4.5 and 5.2. The drug was then diluted daily in saline to a concentration of $100 \mu \mathrm{g} / \mathrm{ml}$ and was administered intravenously into the tail vein at a dose of $100 \mu \mathrm{g} / \mathrm{kg}$ followed by $0.5 \mathrm{ml}$ of saline. Treatments occurred daily (Monday through Friday) for 2 weeks with the dosage calculated on daily body weight. This dosage regimen was chosen because it produced maximal hyperalgesia in the absence of motor impairment in most rats (Aley et al., 1996). Vincristine-treated rats weighed $305 \pm 5 \mathrm{gm}(n=49)$ at the time of electrophysiological recording. Untreated control rats were weightmatched, $317 \pm 6 \mathrm{gm}(n=42)$; previous behavioral experiments demonstrated that repeated intravenous saline injections had no effect on behavioral nociceptive threshold (Aley et al., 1996). Experimental rats were used for electrophysiological recordings during the peak phase of chronic vincristine-induced hyperalgesia that occurred in the absence of the drug, that is, from $1-5 \mathrm{~d}$ after the final injection of vincristine (Fig. $1 A$ ). This recording window was chosen based on behavioral data that showed that the mechanical withdrawal threshold of $>90 \%$ of vincristine-treated rats was decreased $>15 \%$ during these $5 \mathrm{~d}(\mathrm{~K}$. O. Aley and J. D. Levine, unpublished observations). At this dose of vincristine, $18 \%$ of rats developed motor impairment and were not used for electrophysiological recording.

\section{In vivo single-unit electrophysiology}

The single-unit electrophysiological recording techniques used have been described previously (Ahlgren et al., 1992). Briefly, rats were anesthe- tized with pentobarbital sodium (65 mg/kg, i.p.), and additional anesthetic was administered throughout the experiment to maintain areflexia. Recordings were made from the saphenous nerve, the cutaneous nerve that innervates the medial-dorsal hindpaw where mechanical hyperalgesia to vincristine was characterized (Aley et al., 1996). The skin overlying the saphenous nerve was retracted at midthigh level. The nerve was exposed and dissected free from surrounding tissue and vessels and maintained in a pool of $37^{\circ} \mathrm{C}$ mineral oil. Bipolar stimulating electrodes were placed under the nerve at a distal site to enable electrical stimulation (Stimulator S-88; Grass Medical Instruments, Quincy, MA; Stimulus Isolator NL-800; Neurolog; Medical Systems Corporation, Greenvale, $\mathrm{NY}$ ) of peripheral neurons. At a proximal site, a portion of the nerve was desheathed to expose axons. The nerve was crushed proximal to the recording site to prevent the elicitation of flexor reflexes during electrical stimulation of the nerve. Fine fascicles of axons were then dissected from the nerve with sharpened jeweler's forceps and placed on a silver wire recording electrode. Action potentials (APs) from individual fibers were amplified and filtered (Neurolog; Medical Systems Corporation) and then stored on tape (Video Cassette Recorder 420K; A. R. Vetter, Rebersburg, PA), as well as being discriminated by amplitude (Winston Electronics, San Francisco, CA) and displayed on a chart recorder on-line. The animal was killed by pentobarbital overdose at the end of the recording session.

\section{Characterization of fiber types}

Conduction velocity and classification. Conduction velocity was determined by dividing the distance between the recording and stimulating electrodes, which measured between 20 and $33 \mathrm{~mm}$, by the latency of the AP after an electrical stimulus to the whole nerve. Fibers that conducted at $<2 \mathrm{~m} / \mathrm{sec}$ were classified as C-fibers, and those that conducted at $\geq 2$ $\mathrm{m} / \mathrm{sec}$ were classified as A-fibers. Because this study focused on C-fibers, we did not analyze A-fiber subclasses further. The percentage of A-fibers versus $\mathrm{C}$-fibers in the nerve was calculated by dividing the number of neurons in each fiber class by the total number of fibers that could be excited by electrical stimulation of the nerve. To determine the number of electrically excitable fibers in each fascicle, we gradually increased the amplitude of the electrical stimulus $(0.5 \mathrm{msec} ; 0.25 \mathrm{~Hz})$ so that the number of $\mathrm{C}$-fibers present could be counted. This process was repeated for each fascicle using shorter duration $(0.05 \mathrm{msec})$ and higher frequency $(2.5 \mathrm{~Hz})$ electrical stimulation to quantitate the number of myelinated A-fibers present in the fascicle.

Spontaneous activity. To determine the percentage of spontaneously active fibers in the saphenous nerve of control and vincristine-treated rats, we monitored activity in at least 100 fibers for each animal. The percentage of spontaneously active fibers per nerve was calculated by dividing the number of different spontaneously active waveforms present by the total number of electrically excitable fibers observed. No more than 17 A-fibers and C-fibers were recorded simultaneously in any one fascicle and, usually, many fewer. Between 10 and 20 fascicles were monitored in each rat studied. Each fascicle was monitored for $2 \mathrm{~min}$, and 
Figure 2. Vincristine causes a slowing of the conduction velocity of both A-fibers and C-fibers. Conduction velocities were determined by dividing the distance between the recording and stimulating electrodes by the latency of an individual AP from an afferent after an electrical stimulus to the whole nerve. The filled bars represent data from vincristinetreated rats, and the open bars represent data from control rats. $A$, Left, The distribution of $\mathrm{C}$-fiber conduction velocities for 693 vincristine-treated and 401 control C-fibers. Bin width is $0.1 \mathrm{~m} / \mathrm{sec}$. Right, The average C-fiber conduction velocity in control and vincristine-treated rats. These averages were calculated from the values in the histogram on the left. Error bars in this and subsequent figures represent SEM. $B$, Left, The distribution of A-fiber conduction velocities for 561 vincristine-treated and 264 control A-fibers. Bin width is $2 \mathrm{~m} / \mathrm{sec}$. Right, The average A-fiber conduction velocity in control and vincristine-treated rats. These averages were calculated from the values in the histogram on the left.
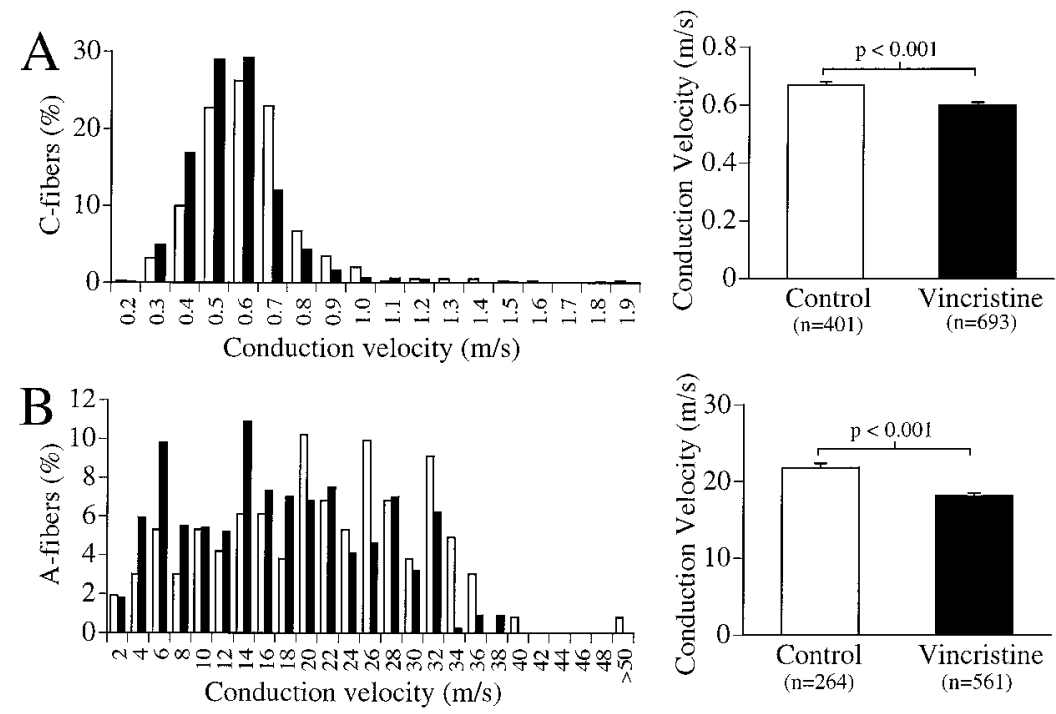

the number of spontaneously active waveforms was quantitated. At most, there were two spontaneously active units per fascicle, and their waveforms could be easily discriminated. For each spontaneously active waveform encountered, the rate of ongoing activity was measured for three consecutive $2 \mathrm{~min}$ observation periods. These three values were averaged, and this number was considered the rate of spontaneous activity for that fiber. If the rate of spontaneous activity was $>1.5 \mathrm{~Hz}$, a heat lamp was directed toward the receptive field to verify that this was a cold-sensitive fiber. In all fibers tested with a spontaneous activity rate of $>1.5 \mathrm{~Hz}$, warming the foot decreased the rate of spontaneous activity. In these spontaneous activity experiments, the skin was never mechanically probed or stimulated with heat, and this prevented any stimulationinduced afterdischarge or sensitization from being misclassified as spontaneous activity. The fiber class of the spontaneously active waveforms was not identified. In a subset of electrophysiological experiments on control and vincristine-treated rats, both the room temperature and the surface temperature of the contralateral hindpaw were measured using a thermocouple and a digital thermometer (Physitemp, Clifton, NJ).

\section{Characterization of $C$-fibers}

Modality classification. The receptive fields of $\mathrm{C}$-fibers were determined using a mechanical search stimulus, either a blunt probe or a $60 \mathrm{gm}$ von Frey hair that activates close to $100 \%$ of $\mathrm{C}$-fibers in the saphenous nerve of the rat (Ahlgren et al., 1992) (see Fig. 3). C-fibers whose receptive fields were being studied were defined as those that showed a slowed conduction velocity in response to electrical stimulation after mechanical stimulation of the receptive field (Fig. $1 B$ ). This test established that the mechanical receptive field under study was innervated by the $\mathrm{C}$-fiber whose latency to electrical stimulation was shifted. The receptive fields of $\mathrm{C}$-fibers were determined to be cutaneous if they were activated by lifting and squeezing the skin or if the mechanically sensitive spot moved to a new location when the skin was moved relative to the subcutaneous tissues. Fibers that did not meet this criterion but were mechanically sensitive were classified as C-deep neurons. All other C-fiber categories were cutaneous. Fibers classified as $\mathrm{C}$-mechanoheats $(\mathrm{C}-\mathrm{MH})$ responded to mechanical and heat stimulation. Fibers classified as $\mathrm{C}$-mechanocolds (C-MC) responded to both mechanical and cold stimulation. Fibers classified as $\mathrm{C}$-cold $(\mathrm{C}-\mathrm{C})$ responded only to cold stimulation. Fibers classified as $\mathrm{C}$-mechanoheatcolds (C-MHC) responded to mechanical, heat, and cold stimulation; it was unclear whether the activation by cold was caused by a mechanical alteration of the skin because these fibers always had mechanical thresholds of $<0.02 \mathrm{gm}$. Fibers classified as $\mathrm{C}$-mechanical (C-M) only responded to mechanical stimulation. For fibers classified as $\mathrm{C}$-silent, it was not possible to identify a mechanical receptive field; this category presumably included both sympathetic postganglionic neurons and mechanically insensitive, silent fibers and was not evaluated further.

Mechanical activation threshold. Mechanical activation thresholds were determined using a series of von Frey hairs (VFHs) that ranged in intensity from 0.02 to $263 \mathrm{gm}$ (A. Ainsworth, London, England). The mechanical threshold was defined as the intensity in grams of the weakest VFH to which the fiber fired more than two APs in $50 \%$ of the trials.
Each trial consisted of a brief $(\sim 1 \mathrm{sec})$ application of a $\mathrm{VFH}$ to the center of the receptive field. VFHs were applied in ascending order, and 5-10 trials were performed for each VFH tested. Threshold was verified by alternately testing the strongest ineffective $\mathrm{VFH}$ and the weakest effective VFH. Such repeated mechanical testing of C-fibers does not cause a change in mechanical threshold (Ahlgren et al., 1992; K. D. Tanner and J. D. Levine, unpublished observations).

Heat activation threshold. Heat activation thresholds were determined using a Peltier device (Thermal Devices Inc., Minneapolis, MN) that delivered a ramped heat stimulus from 30 to $58^{\circ} \mathrm{C}$ at a rate of $1^{\circ} \mathrm{C} / \mathrm{sec}$. After the Peltier device was placed on the receptive field of a $\mathrm{C}$-fiber, activity was monitored for 2 min to verify the absence of mechanically induced activity. The heat threshold was defined as the temperature at which the C-fiber fired a second AP. The heat activation threshold was determined twice with a 10 min interstimulus interval. The average of these two measurements was the heat activation threshold for that fiber.

Cold activation. Cold responsiveness was determined using the Peltier device that delivered a ramped cold stimulus from 30 to $0^{\circ} \mathrm{C}$ at a rate of $\sim 1^{\circ} \mathrm{C} / \mathrm{sec}$. After the Peltier device was placed on the receptive field of a $\mathrm{C}$-fiber, activity was monitored for 2 min to verify the absence of any mechanically induced activity. Cold responsiveness was defined as an increase in the rate of ongoing activity in a fiber in response to cooling. Threshold was not determined in these fibers because of the presence of ongoing activity. Cold responsiveness was defined as an increase in the rate of ongoing activity in a fiber in response to placing either ice or a cooled metal probe above or on the receptive field. In addition, cold responsiveness was verified by the presence of a decrease in the rate of ongoing activity in a fiber in response to directing a radiant heat lamp toward the receptive field of the fiber.

Sustained mechanical stimulation. Sustained mechanical stimulation of receptive fields was accomplished by use of a mechanical stimulation device consisting of a force transducer (Model ELF-TC500-1; Entran Devices, Inc., Fairfield, NJ) with a response range of 1-400 gm mounted in series with a receptacle that can interchangeably hold von Frey hair filaments (modified from a set of VFHs from Stoelting, Wood Dale, IL) that deliver various gram weight stimuli. A $10 \mathrm{gm}$ mechanical stimulus was chosen to examine the response properties of nociceptive afferents because this stimulus is suprathreshold for $>90 \%$ of C-fibers in the saphenous nerve (see Fig. 3). VHFs were used because they are able to compensate well for changes in tissue elasticity over time, unlike rigid probes. The VFH was applied to the receptive field, by hand, and maintained at the just-bent position for $1 \mathrm{~min}$. The voltage output signal from the force transducer was a quantitative measure of the force applied to the receptive field and was sent to both a chart recorder and a videocassette recorder tape for display, storage, and off-line analysis.

For each fiber whose response to prolonged stimulation was studied, the conduction velocity, receptive field location, baseline spontaneous activity, and mechanical threshold were determined. Because of physical constraints, only C-fibers with receptive fields below the ankle were studied. To avoid inadvertently recording the response properties of slowed A $\delta$-fibers (see Fig. 2; Results), we studied only C-fibers that 
Table 1. Spontaneous activity in the saphenous nerve of control and vincristine-treated rats

\begin{tabular}{|c|c|c|c|c|}
\hline & $\begin{array}{l}\text { Spontaneously active } \\
\text { neurons }(\%)\end{array}$ & $\begin{array}{l}\text { Rate of spontaneous } \\
\text { activity (APs/min) }\end{array}$ & $\begin{array}{l}\text { Spontaneously active neurons } \\
\text { with }>100 \mathrm{AP} / \mathrm{min}(\%)\end{array}$ & $\begin{array}{l}\text { Skin surface } \\
\text { temperature }\left({ }^{\circ} \mathrm{C}\right)\end{array}$ \\
\hline Control & $7.0 \pm 0.8(8 \dagger)$ & $120.5 \pm 24.4(61)$ & $34.4(21)$ & $24.6 \pm 0.7(9 \dagger)$ \\
\hline Vincristine-treated & $5.7 \pm 0.6(14 \dagger)$ & $85.6 \pm 23.4(84)$ & $16.7^{*}(14)$ & $24.2 \pm 0.7(9 \dagger)$ \\
\hline
\end{tabular}

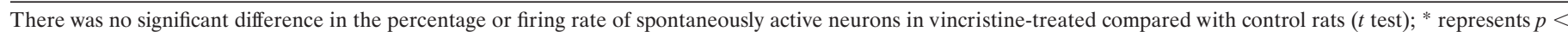

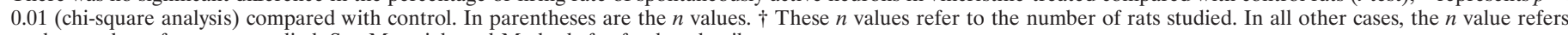
to the number of neurons studied. See Materials and Methods for further details.

conducted at $<1 \mathrm{~m} / \mathrm{sec}$. Because some vincristine-treated fibers develop an afterdischarge after mechanical stimulation (data not shown), we did not record from $\mathrm{C}$-fibers that fired more than five APs per minute during the 2 min observation period to avoid recording from those fibers that may have developed ongoing activity after mechanical search stimulation of the skin; these fibers comprised $<10 \%$ of the population. In general, the prolonged stimulation protocol consisted of four trials of sustained 1 min mechanical stimulation with a 10 min interstimulus interval between trials. The average of these four trials was the sustained mechanical stimulation response for that fiber and usually had a SEM of $<10 \%$. In a small number of cases included in the analysis, more trials were conducted to reduce the SEM, or fewer trials were conducted because the fiber was lost. Activity was monitored for $5 \mathrm{~min}$ after the removal of the mechanical stimulus to quantitate afterdischarge.

Suprathreshold heat stimulation. For 16 of 37 control and 19 of 39 vincristine-treated nociceptors studied, responsiveness to heat stimulation was also assayed. Suprathreshold heat stimulation of receptive fields consisted of a ramped stimulus that began from a base temperature of $30^{\circ} \mathrm{C}$ and went to a maximum of $53^{\circ} \mathrm{C}$ at a rate of $1^{\circ} \mathrm{C} / \mathrm{sec}$; after reaching maximum temperature, the stimulus was terminated such that there was almost no time spent at the maximum temperature. This protocol was used for all nociceptors irrespective of threshold. This ramped heat stimulation protocol was chosen because square wave heat stimuli resulted in profound inactivation of $\mathrm{C}$-fiber nociceptor responses during even a $10 \mathrm{sec}$ trial. Preliminary experiments showed that nociceptor responses were most reproducible to ramped heat stimuli at this stimulation rate and maximum temperature (Tanner and Levine, unpublished observations). After determination of heat threshold, three heat ramp stimuli were delivered to the receptive field of each fiber at an interstimulus interval of $20 \mathrm{~min}$. Unfortunately, even at this long interstimulus interval, there was partial desensitization of the heat response with subsequent trials in many neurons. Thus, heat responses were not averaged, and the response to only the first heat stimulus was used in all analyses. Because of physical constraints related to the size of the Peltier thermal stimulator, only nociceptors with receptive fields distal to the ankle were studied.

Data analysis. Data are expressed as mean \pm SEM. Statistical analyses were done using Student's $t$ test, ANOVA, chi-square analysis, or the Mann-Whitney $U$ test, as appropriate.

\section{RESULTS}

In this study, data presented were collected in two sets of experiments. Data concerning spontaneous activity and the proportion of A-fibers and C-fibers were collected from a sample of 871 neurons in 8 control rats and 1474 neurons in 14 vincristinetreated rats. Conduction velocity was measured in a subset of these experiments from a sample of $401 \mathrm{C}$-fibers and $264 \mathrm{~A}$-fibers in 6 control rats and $693 \mathrm{C}$-fibers and 561 A-fibers in 12 vincristine-treated rats. All other data, including the distribution of C-fibers among functional subclasses, mechanical and heat thresholds, and mechanical and heat responsiveness, were collected from a total of $76 \mathrm{C}$-fibers in 52 control rats and $72 \mathrm{C}$-fibers in 63 vincristine-treated rats. Vincristine-treated rats did not gain weight normally during the course of the treatment, as has been described previously (Aley et al., 1996). There was an average decrease in body weight during vincristine treatment of $7.1 \pm$ $1.4 \%$, although this varied substantially from rat to rat.

\section{Vincristine causes a slowing of the conduction velocity of sensory neurons}

As shown in Figure $2 A$, the mean conduction velocity of C-fibers in vincristine-treated rats $(0.60 \pm 0.006 \mathrm{~m} / \mathrm{sec} ; n=693)$ is significantly $(p<0.001)$ slower than that of $\mathrm{C}$-fibers in control rats $(0.67 \pm 0.01 \mathrm{~m} / \mathrm{sec} ; n=401)$. Similarly, as shown in Figure $2 B$, the mean conduction velocity of A-fibers in vincristinetreated rats $(18.1 \pm 0.4 \mathrm{~m} / \mathrm{sec} ; n=561)$ is significantly $(p<$ $0.001)$ slower than that of A-fibers in control rats $(21.8 \pm 0.6$ $\mathrm{m} / \mathrm{sec} ; n=264)$.

\section{Vincristine does not increase spontaneous activity in sensory neurons}

As shown in Table 1, both the percentage of spontaneously active fibers and the average rate of spontaneous activity for those neurons with spontaneous activity are lower in vincristine-treated rats than in control rats. These differences, although not significant $(p>0.05, t$ test $)$, reflect a significant $(p<0.02$, chi-square analysis) decrease in the proportion of fibers that have rates of spontaneous activity $>1.5 \mathrm{~Hz}$. In both vincristine-treated and control rats, the distribution of rates of spontaneous activity was bimodal with peaks at $<0.02$ and $>1.5 \mathrm{~Hz}$ (data not shown). However, in vincristine-treated rats, there was less than one-half as many fibers with firing rates $>1.5 \mathrm{~Hz}$ than there was in control rats. The range of spontaneous activity rates observed in control fibers $(0.01-13.2 \mathrm{~Hz})$ was similar to that observed in vincristinetreated fibers $(0.01-18.9 \mathrm{~Hz})$. In all cases tested (18 of 21 control and 8 of 14 vincristine-treated fibers), fibers with rates of spontaneous activity $>1.5 \mathrm{~Hz}$ were cold-sensitive. To verify that this difference in the spontaneous activity of cold-sensitive fibers was not attributable to differences in skin temperature, we measured the paw temperatures of anesthetized vincristine-treated and control rats and averaged the temperatures over the course of the recording session. There was no significant difference $(p>0.05)$ between the paw temperature of control $\left(24.6 \pm 0.7^{\circ} \mathrm{C} ; n=9\right)$ and of vincristine-treated $\left(24.2 \pm 0.7^{\circ} \mathrm{C} ; n=9\right)$ rats.

\section{Vincristine does not cause a selective loss of A-fibers or C-fibers}

The proportion of A-fibers (44.6 $\pm 1.4 \% ; n=14$ rats) and C-fibers $(55.4 \pm 1.4 \% ; n=14$ rats) recorded in the saphenous nerve of vincristine-treated rats is similar $(p>0.05)$ to the proportion of A-fibers $(41.2 \pm 1.6 \% ; n=8$ rats) and C-fibers $(58.8 \pm 1.6 \% ; n=8$ rats) in control rats.

\section{Vincristine does not alter the distribution of $\mathbf{C}$-fibers among functional subclasses}

C-fiber afferents $(n=33)$ from vincristine-treated rats have a similar distribution among functional subclasses [C-MH $(57.6 \%$; $n=19), \mathrm{C}-\mathrm{M}(6.1 \% ; n=2), \mathrm{C}-\mathrm{MC}(3 \% ; n=1), \mathrm{C}-\mathrm{C}(6.1 \% ; n=$ 2), C-MHC (0\%; $n=0)$, C-deep $(18.2 \% ; n=6)$, and C-silent $(9.1 \% ; n=3)]$ as do $\mathrm{C}$-fiber afferents $(n=43)$ from control rats 
Figure 3. Vincristine does not decrease the heat or mechanical activation thresholds of C-fiber nociceptors. $A$, Left, The distribution of $\mathrm{C}$-fiber heat activation thresholds for 37 vincristine-treated and 45 control $\mathrm{C}$-fibers. Right, The average heat activation threshold for control C-fibers (open bars) and for vincristine-treated C-fibers ( filled bars). Bin width is $2^{\circ} \mathrm{C}$. B, Left, The distribution of $\mathrm{C}$-fiber mechanical thresholds for 57 vincristine-treated and 60 control C-fibers. Right, The average mechanical activation threshold for control C-fibers (open bars) and for vincristine-treated $\mathrm{C}$-fibers ( filled bars). Each bin on the $x$-axis is the intensity in grams of a VFH used to test C-fiber mechanical threshold, with the exception of the " $>60$ " bin that combines all VFHs of intensities $>60 \mathrm{gm}$.
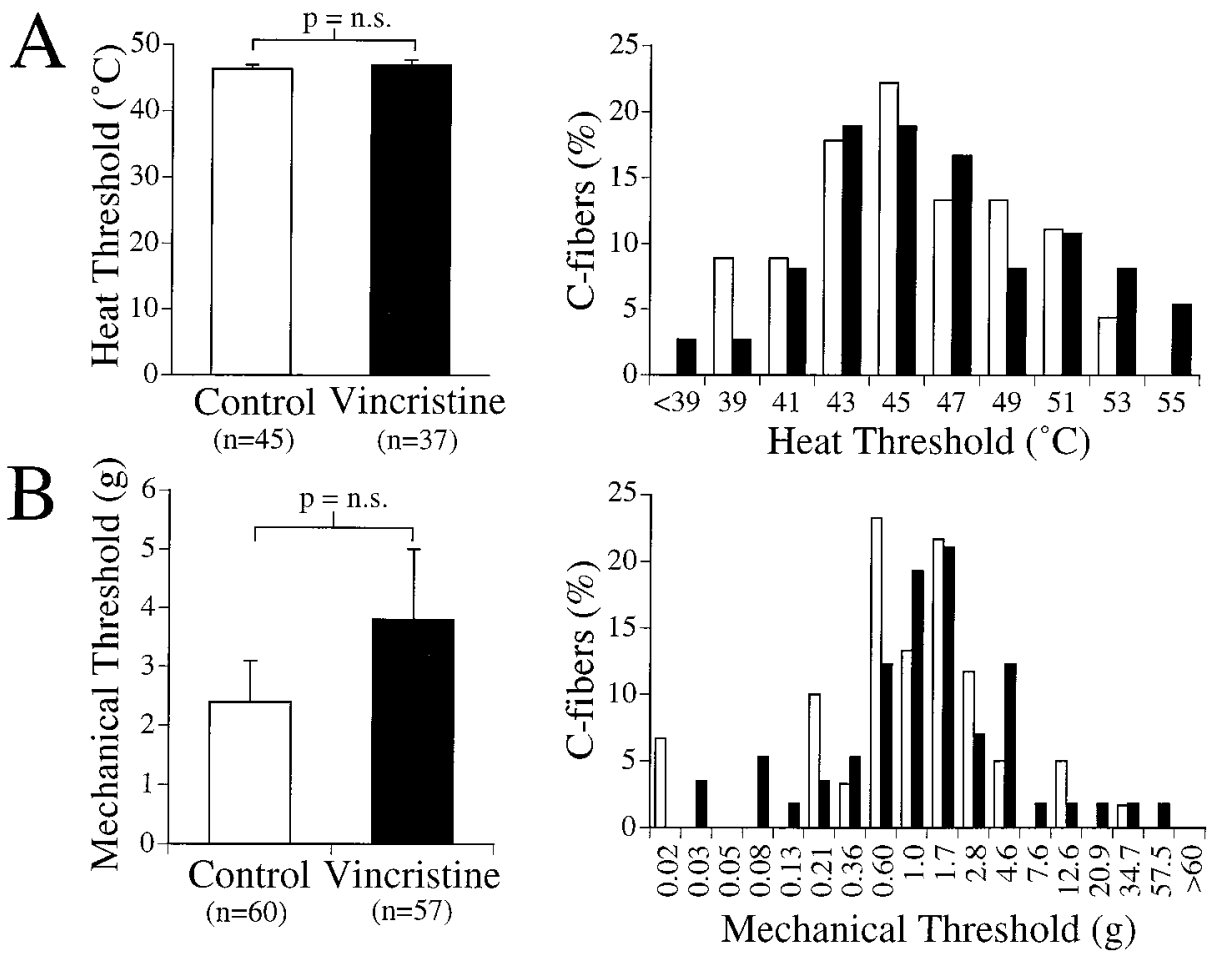

[C-MH (62.8\%; $n=27), \mathrm{C}-\mathrm{M}(2.3 \% ; n=1), \mathrm{C}-\mathrm{MC}(4.7 \%$; $n=2), \mathrm{C}-\mathrm{C}(2.3 \% ; n=1), \mathrm{C}-\mathrm{MHC}(7 \% ; n=3)$, C-deep $(16.3 \%$; $n=7)$, and $\mathrm{C}$-silent $(4.7 \% ; n=2)](p>0.05$, chi-square analysis). Of note, there is no decrease in the percentage of cold-responsive $\mathrm{C}$-fibers in vincristine-treated rats compared with that in control rats.

\section{Vincristine does not decrease the heat or mechanical activation thresholds of C-fibers}

In addition, as shown in Figure $3 A$, the average heat threshold of vincristine-treated C-fibers $\left(46.9 \pm 0.8^{\circ} \mathrm{C} ; n=37\right)$ is not statistically different $(p>0.05)$ from that of control C-fibers $(46.3 \pm$ $\left.0.6^{\circ} \mathrm{C} ; n=45\right)$. As shown in Figure $3 B$, the average mechanical threshold for vincristine-treated C-fibers $(3.8 \pm 1.2 \mathrm{gm} ; n=57)$ was higher than, but not significantly different from ( $p=0.40$, Mann-Whitney $U$ test), the average mechanical threshold for control C-fibers $(2.4 \pm 0.7 \mathrm{gm} ; n=60)$.

\section{Vincristine increases responsiveness to sustained mechanical stimulation in a subset of $\mathbf{C}$-fibers}

To assay responsiveness of $\mathrm{C}$-fibers to sustained mechanical stimulation, we delivered a $10 \mathrm{gm}$ stimulus to the receptive field for 1 min. Examples of responses of $\mathrm{C}$-fibers from control and vincristine-treated rats are shown in Figure 4. Figure $4 A$ shows the poststimulus time histogram response to a mechanical stimulus of a representative $\mathrm{C}$-fiber from a control rat that had a mechanical threshold of $1.7 \mathrm{gm}$ and a conduction velocity of 0.78 $\mathrm{m} / \mathrm{sec}$. Figure $4 B$ shows the poststimulus time histogram response to a mechanical stimulus of a $\mathrm{C}$-fiber from a vincristine-treated rat that also had a mechanical threshold of $1.7 \mathrm{gm}$, and a conduction velocity of $0.62 \mathrm{~m} / \mathrm{sec}$. This vincristine-treated $\mathrm{C}$-fiber fired more than twice as many APs as did the control C-fiber and is representative of a subpopulation of mechanically hyperresponsive $\mathrm{C}$-fibers found in vincristine-treated rats.

A histogram of the distribution of C-fiber responses to a $10 \mathrm{gm}$, 1 min sustained mechanical stimulus is plotted for all C-fibers studied from control and vincristine-treated rats in Figure 5. Whereas the responses of $\mathrm{C}$-fibers from control rats are clustered in a unimodal distribution in the 50-59 AP bin, the responses of $\mathrm{C}$-fibers from vincristine-treated rats form two distinct clusters in a bimodal distribution with a cluster around 50-59 APs per stimulus and another at 100-109 APs per stimulus and greater. The responses of $59 \%$ of vincristine-treated C-fibers $(n=23)$ were similar to the responses of control $\mathrm{C}$-fibers. This group of C-fibers, defined as those that fire $<100 \mathrm{AP}$ in response to sustained mechanical stimulation, will be referred to as "lowfiring" C-fibers. The other $41 \%$ of vincristine-treated C-fibers were hyper-responsive $(n=16)$, firing approximately twice as many APs as was seen in the response of a typical control C-fiber, and will be referred to as "high-firing" C-fibers. Of $33 \mathrm{C}$-fibers studied from control rats, only one had a response similar to those of the subpopulation of high-firing, hyper-responsive C-fibers in vincristine-treated rats (see Fig. 5). Interestingly, the responses of control C-fibers were quite similar to each other, regardless of the fibers' mechanical thresholds that ranged from 0.4 to $4.6 \mathrm{gm}$ (see Figs. 3, 10C).

Figure 6 shows the time course of the average $\mathrm{C}$-fiber responses to sustained mechanical stimulation in control and vincristinetreated rats. As seen in Figure $6 A$, the time course of the average response of all vincristine-treated $\mathrm{C}$-fibers ( $\boldsymbol{\square})$ to a sustained mechanical stimulus, including both low-firing and high-firing C-fibers, was significantly $(p<0.01)$ greater than was the average response of all control C-fibers $(\square)$. As seen in Figure $6 B$, when vincristine-treated $\mathrm{C}$-fibers are considered as two distinct populations, the time course of the average response of low-firing vincristine-treated $\mathrm{C}$-fibers $(\bullet)$ is indistinguishable $(p>0.05)$ from that of all control $\mathrm{C}$-fibers $(\square)$; however, the average response, over time, of high-firing vincristine-treated $\mathrm{C}$-fibers $(\boldsymbol{\Delta})$ was significantly increased $(p<0.0001)$ compared with that of all control C-fibers $(\square)$. The hyper-responsiveness in vincristinetreated $\mathrm{C}$-fibers occurs during the burst but is more pronounced 
A Control
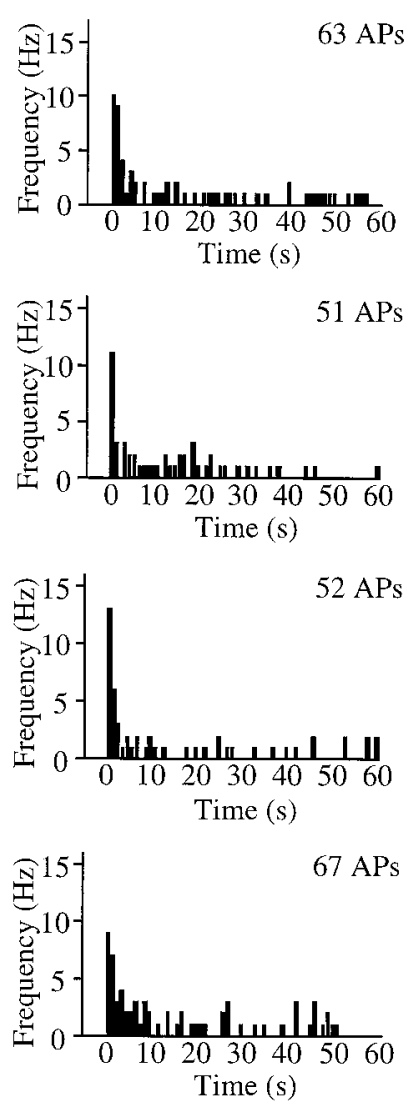

B

\section{Vincristine}
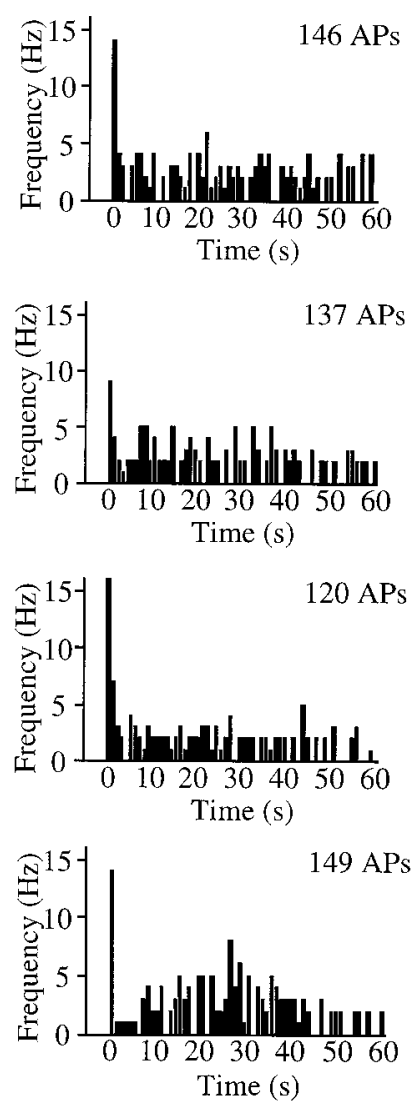

Figure 4. Vincristine causes increased responsiveness to sustained mechanical stimulation in a subset of $\mathrm{C}$-fibers. $A$, The response of a $\mathrm{C}$-fiber from a control rat. This fiber had a conduction velocity of $0.78 \mathrm{~m} / \mathrm{sec}$, had a mechanical threshold of $1.7 \mathrm{gm}$, and fired no APs during the $2 \mathrm{~min}$ immediately preceding stimulation (only the last $10 \mathrm{sec}$ is shown). The fiber fired 63,51, 52, and 67 APs during the four stimulation trials for an average of $58.3 \pm 4.0$ APs per stimulation. The peak firing frequency during the burst for the four trials was $10,11,13$, and $9 \mathrm{~Hz}$, respectively. $B$, The response of a hyper-responsive $\mathrm{C}$-fiber from a vincristine-treated rat. This fiber had a conduction velocity of $0.62 \mathrm{~m} / \mathrm{sec}$, had a mechanical threshold of $1.7 \mathrm{gm}$, and fired no APs during the $2 \mathrm{~min}$ immediately preceding stimulation. The fiber fired 146, 137, 120 , and 149 APs during the four stimulation trials for an average of $138 \pm 6.5$ APs per stimulation. The peak firing frequency during the burst for the four trials was $14,9,16$, and $14 \mathrm{~Hz}$, respectively. Bin width is $1 \mathrm{sec}$. during the plateau phase of the C-fiber response (10-60 sec after the onset of the stimulus).

As shown in Table 2, the increased responsiveness in highfiring vincristine-treated $\mathrm{C}$-fibers was significant $(p<0.01)$ both during the burst (first $10 \mathrm{sec}$ ) and the plateau (last $50 \mathrm{sec}$ ) of the $1 \mathrm{~min}$ response. Interestingly, there was also an increased level of afterdischarge during the $5 \mathrm{~min}$ after the stimulus in high-firing vincristine-treated $\mathrm{C}$-fibers compared with that in low-firing vincristine-treated or control $\mathrm{C}$-fibers. This increase in afterdischarge occurred in only a subset of high-firing vincristine-treated C-fibers and was not statistically significant for the total population of high-firing vincristine-treated nociceptors.

\section{Vincristine causes heat hyper-responsiveness in high- firing vincristine-treated nociceptors}

In a subset of neurons, we tested the hypothesis that high-firing vincristine-treated nociceptors, which are hyper-responsive to mechanical stimulation, are also hyper-responsive to heat stimulation. Figure 7 shows examples of responses to mechanical stimulation (1 $\mathrm{min} ; 10 \mathrm{gm})$ and heat stimulation (ramp from 30 to $53^{\circ} \mathrm{C}$ at $1{ }^{\circ} \mathrm{C} / \mathrm{sec}$ ) for a control nociceptor and a low-firing and a high-firing vincristine-treated nociceptor that had similar mechanical and heat activation thresholds. This high-firing vincristine-treated nociceptor fired more than twice as many APs as did the control or low-firing vincristine-treated nociceptors for both mechanical and heat stimulation. Thus, high-firing vincristine-treated nociceptors can be hyper-responsive to both mechanical and heat stimulation.

\section{Heat hyper-responsiveness occurs in high-firing but not in low-firing vincristine-treated nociceptors}

In Figure 8 the average responses to mechanical stimulation are plotted for all control and all vincristine-treated C-fibers, as well as for low-firing vincristine-treated and high-firing vincristinetreated C-fibers separately. As first shown in Figure 6, the averaged response to mechanical stimulation for all vincristinetreated $\mathrm{C}$-fibers is significantly greater than that for control C-fibers (Fig. $8 A, p<0.05$ ). In addition, the averaged response of high-firing vincristine-treated $\mathrm{C}$-fibers to mechanical stimulation is significantly greater compared with the averaged response for either low-firing vincristine-treated C-fibers $(p<0.01)$ or control C-fibers $(p<0.01)$. Although a similar pattern is seen when the average responses to heat stimulation are plotted (Fig. $8 B$ ), the response to heat stimulation for all vincristine-treated $\mathrm{C}$-fibers is not significantly greater than that for control C-fibers $(p>0.05)$. High-firing vincristine-treated $\mathrm{C}$-fibers do, however, have a significantly greater response to heat stimulation when compared with either low-firing vincristine-treated C-fibers $(p<0.01)$ or control C-fibers $(p<0.01)$.

\section{Heat hyper-responsiveness occurs in some, but not all, high-firing vincristine-treated nociceptors}

Although heat hyper-responsiveness can accompany mechanical hyper-responsiveness in high-firing vincristine-treated nociceptors, this is not always the case. In Figure $9 A$, the magnitude of the heat response is plotted against the mechanical response for each nociceptor studied. Whereas the mechanical responses of high- 
Figure 5. The responses of C-fibers to sustained mechanical stimulation in vincristine-treated rats are bimodal. The total number of APs fired in response to $1 \mathrm{~min}$ of $10 \mathrm{gm}$ stimulation of the receptive field is plotted for 37 control C-fibers (open bars) and 39 vincristine-treated C-fibers (filled bars). The percentage of $\mathrm{C}$-fibers that fired $>100$ APs in response to the $1 \mathrm{~min} 10 \mathrm{gm}$ stimulus, referred to as high-firing C-fibers, is $2.7 \%$ of control C-fibers ( 1 of 37 ) and $41 \%$ of vincristine-treated C-fibers (16 of 39).

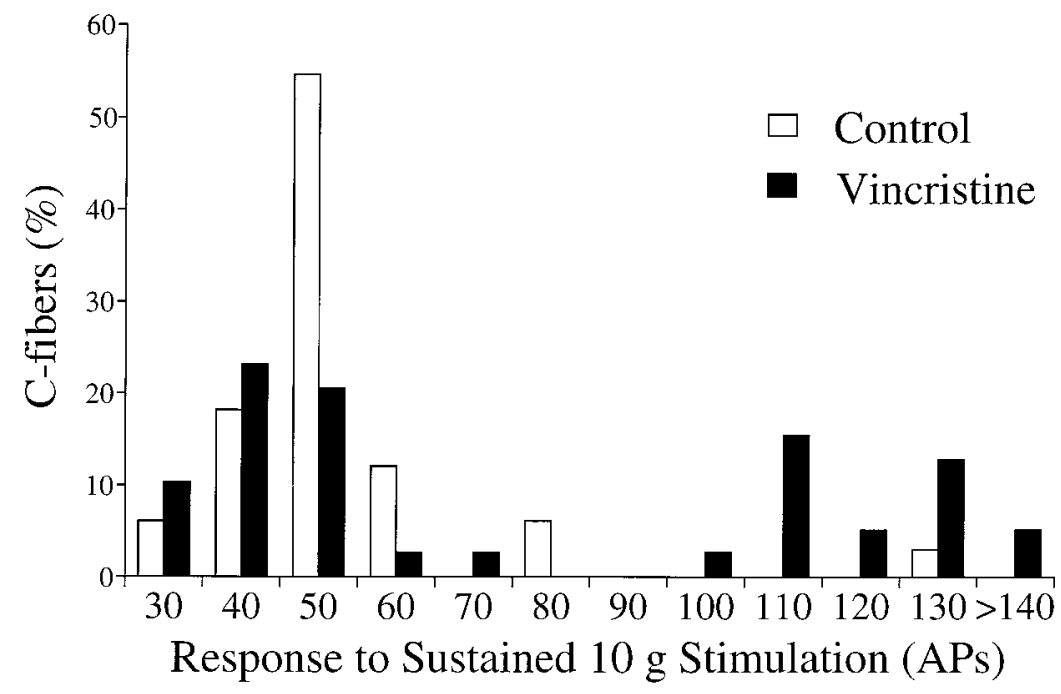

firing vincristine-treated nociceptors are all clearly much higher than are those of control and low-firing vincristine-treated nociceptors, only a subset of the heat responses of high-firing vincristine-treated nociceptors exceed those of control and lowfiring vincristine-treated nociceptors. However, because the magnitude of the heat response is correlated with the heat activation threshold of the neuron (Fig. 9B), those high-firing vincristinetreated nociceptors that do not appear to have heat responses higher than those of controls in Figure $9 A$ could simply have higher heat thresholds. To determine whether this could account for the apparent lack of heat hyper-responsiveness in some highfiring vincristine-treated nociceptors, we plotted the response to heat stimulation against heat threshold for each neuron (Fig. 9B). Note that some high-firing vincristine-treated nociceptors have heat responses greater than or at the high end of those for control and low-firing vincristine-treated nociceptors with similar heat thresholds; however, the remaining high-firing vincristine-treated nociceptors are well within the range of heat responses of control and low-firing vincristine-treated nociceptors. Thus, the range of heat thresholds in high-firing vincristine-treated nociceptors is unlikely to account for the lack of heat hyper-responsiveness in some high-firing vincristine-treated nociceptors.

\section{Mechanical hyper-responsiveness in C-fiber nociceptors is not correlated with receptive field location, conduction velocity, mechanical threshold, or heat threshold}

Lastly, as shown in Figure 10, hyper-responsiveness in the subpopulation of high-firing $\mathrm{C}$-fibers in vincristine-treated rats does not correlate with receptive field location, conduction velocity, or mechanical or heat threshold. The data presented in Figure 10 are from those $\mathrm{C}$-fibers whose responses to sustained mechanical stimulation were studied. As shown in Figure $10 A$, high-firing $\mathrm{C}$-fibers in vincristine-treated rats do not appear to be located in any specific skin regions of the dorsal hindpaw. As shown in Figure $10 \mathrm{~B}$, the average conduction velocity of all vincristinetreated C-fibers $(0.76 \pm 0.01 \mathrm{~m} / \mathrm{sec} ; n=39)$ was slightly slower than the average conduction velocity of all control $\mathrm{C}$-fibers $(0.78 \pm 0.01 \mathrm{~m} / \mathrm{sec} ; n=33)$, consistent with previous findings (see Fig. $2 A)$. The average conduction velocity of hyper-responsive, high-firing $\mathrm{C}$-fibers $(0.73 \pm 0.02 \mathrm{~m} / \mathrm{sec} ; n=16)$ was slightly slower but not significantly different from $(p>0.05)$ the average conduction velocity of low-firing C-fibers $(0.78 \pm 0.02 \mathrm{~m} / \mathrm{sec} ; n=23)$.
As shown in Figure $10 C$, there was no significant difference between the average mechanical threshold of all control C-fibers $(1.7 \pm 0.2 \mathrm{gm} ; n=33)$ and that of all vincristine-treated $\mathrm{C}$-fibers $(2.2 \pm 0.3 \mathrm{gm} ; n=39)$, although there was a trend for vincristinetreated $\mathrm{C}$-fibers to have higher mechanical thresholds, consistent with our previous findings (see Fig. 3). In addition, the average mechanical threshold of low-firing C-fibers $(2.2 \pm 0.3 \mathrm{gm} ; n=23)$ in vincristine-treated rats was similar $(p>0.05)$ to that of hyper-responsive, high-firing $\mathrm{C}$-fibers $(2.1 \pm 0.4 \mathrm{gm} ; n=16)$ in vincristine-treated rats. As shown in Figure $10 \mathrm{D}$, the average heat threshold of all vincristine-treated C-fibers $\left(45.6 \pm 1.0^{\circ} \mathrm{C}\right.$; $n=19)$ was not significantly different from that of all control C-fibers $\left(45.2 \pm 1.1^{\circ} \mathrm{C} ; n=12\right)$. The average heat threshold of low-firing $\mathrm{C}$-fibers $\left(46.3 \pm 1.4^{\circ} \mathrm{C} ; n=12\right)$ in vincristine-treated rats was not different $(p>0.05)$ from the average mechanical threshold of hyper-responsive, high-firing $\mathrm{C}$-fibers $\left(44.6 \pm 0.9^{\circ} \mathrm{C}\right.$; $n=7$ ) in vincristine-treated rats.

\section{DISCUSSION}

The neural mechanisms underlying neuropathic pain after a wide variety of insults to peripheral nerves including metabolic disorders, traumatic injury, and neurotoxic drugs are for the most part unknown. Specifically, the neural mechanisms of chemotherapyinduced neuropathic pain that occurs in cancer patients and that is caused by neurotoxic drugs such as vincristine and taxol have not been investigated. In this study, we have characterized C-fiber nociceptor function during the peak phase of vincristine-induced painful neuropathy in rat. The finding that almost half of vincristine-treated C-fibers exhibit a marked hyperresponsiveness to suprathreshold mechanical stimulation while most other aspects of nociceptor function were unaffected is striking. There was no increase in C-fiber sensitivity as measured by mechanical and heat activation thresholds; rather there was a trend for the mechanical activation thresholds of $\mathrm{C}$-fibers to be higher than that of controls. Interestingly, there was also no increase in the level of spontaneous activity, a change that has been reported in other models of neuropathic pain (Wall and Gutnick, 1974; Xie and Xiao, 1990; Kajander and Bennett, 1992; Devor, 1994). A significant slowing of conduction velocity was evident in sensory fibers from both the A-fiber and C-fiber classes, consistent with the magnitude of slowing seen in humans with vincristine-induced neuropathy (McLeod and Penny, 1969; 

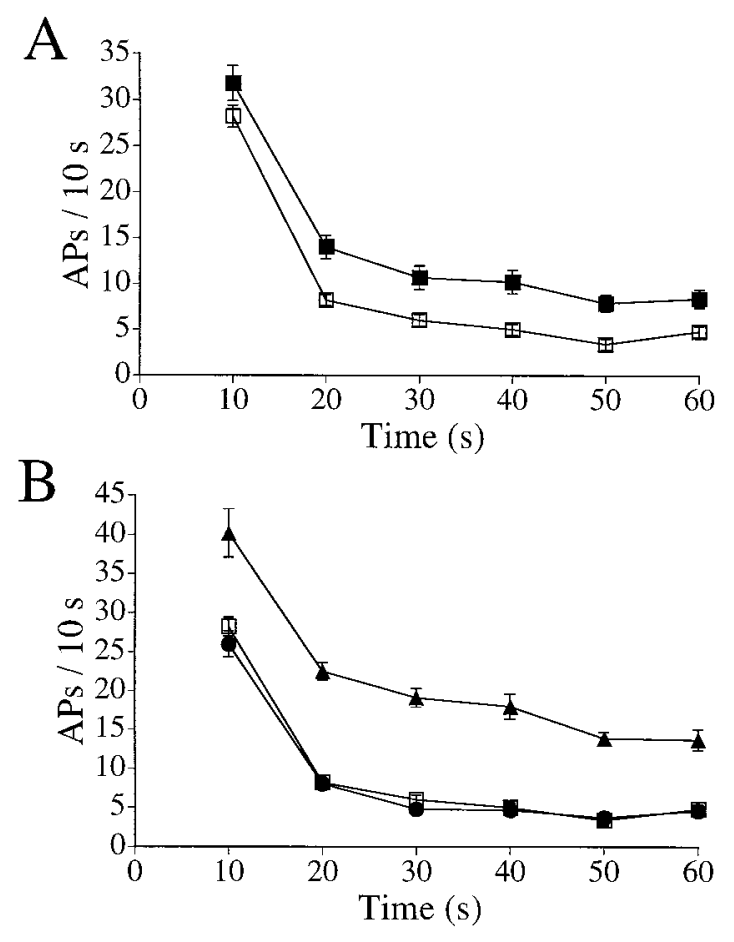

Figure 6. Time course of responses to sustained mechanical stimulation in control and vincristine-treated $\mathrm{C}$-fibers. $A$, The average time course of the response of $\mathrm{C}$-fibers to sustained mechanical stimulation to the receptive field plotted for all control C-fibers $(\square ; n=37)$ and all vincristine-treated C-fibers $(\square ; n=39)$. $B$, The average time course of the response to sustained mechanical stimulation to the receptive field plotted for high-firing vincristine-treated $\mathrm{C}$-fibers firing more than $100 \mathrm{APs}$ during stimulation $(\mathbf{\Delta} ; n=16)$, for low-firing vincristine-treated $\mathrm{C}$-fibers firing less than 100 APs during stimulation $(\mathbf{0} ; n=23)$, and for all control $\mathrm{C}$-fibers $(\square ; n=37)$. Bin width is $10 \mathrm{sec}$. Some error bars are contained within the symbols.

Casey et al., 1973; although see Sandler et al., 1969). These data suggest that vincristine interferes with mechanisms underlying suprathreshold responsiveness rather than causes a generalized impairment of C-fiber nociceptor function. Finally, vincristine also causes heat hyper-responsiveness of vincristine-treated nociceptors that are also mechanically hyper-responsive. Thus, mechanisms of vincristine-induced nociceptor hyperresponsiveness may affect general cellular adaptation mechanisms that mediate nociceptor responses to multiple stimulus modalities. Heat hyper-responsiveness, however, was pronounced in only a subset of mechanically hyper-responsive nociceptors and was never detected in the absence of mechanical hyperresponsiveness, suggesting that vincristine may also specifically alter mechanotransduction in a subset of vincristine-treated nociceptors.

\section{Mechanisms of vincristine-induced nociceptor mechanical and heat hyper-responsiveness}

The mechanisms by which vincristine causes both heat and mechanical hyper-responsiveness in nociceptors are likely to involve its actions on the microtubular cytoskeleton. In fact, recent ultrastructural analysis of unmyelinated axons in the peripheral nerve of vincristine-treated rats revealed disorientation of microtubules during the period of nociceptor hyper-responsiveness and behavioral hyperalgesia (Tanner et al., 1998). Although described in sensory axons, this cytoskeletal disorganization may also occur in nerve terminals because vincristine is thought to act on labile microtubules that are enriched in the nerve terminal (Binet et al., 1990; Ahmad and Baas, 1993). Because vincristine-treated nociceptors can be hyper-responsive either to both heat and mechanical stimulation or to mechanical stimulation only, multiple mechanisms may underlie vincristine-induced hyper-responsiveness of nociceptors.

\section{Mechanisms of hyper-responsiveness to multiple stimulus modalities}

Hyper-responsiveness to multiple stimulus modalities might occur because of alterations in axonal transport, as has been hypothesized previously (Shelanski and Wisniewski, 1969; Bradley et al., 1970; Casey et al., 1973; Weiss et al., 1974). Although axonal microtubules are known to support fast and slow axonal transport of cellular components both anterogradely and retrogradely (Sheetz et al., 1989; Allan et al., 1991; Cleveland and Hoffman, 1991; Sheetz and Martenson, 1991; Hirokawa, 1993), the extent to which the disorientation observed in axonal microtubules in vincristine-induced neuropathy would affect axonal transport is unclear. If axonal transport was impaired, cytoskeletal disorganization could produce alterations of the complement of proteins present in the nerve terminal and secondarily cause changes in the excitability of nociceptors that are independent of stimulus modality, as has been suggested for the axotomy model of neuropathy (Devor et al., 1993).

In addition, vincristine-induced disorientation of nerve terminal microtubules could disrupt adaptation mechanisms that occur during neuronal responses to all modalities of suprathreshold stimulation. Several lines of evidence suggest that the cytoskeleton is involved in the anchoring of ion channels and receptors, as well as in the desensitization of some of these receptors after activation (Srinivasan et al., 1988; Bigot and Hunt, 1990; Kirsch et al., 1991; Rosenmund and Westbrook, 1993). If conductances involved in the adaptation in polymodal nociceptors were regulated by the microtubular cytoskeleton, then vincristine might impair general adaptation mechanisms in the nerve fiber terminal and produce hyper-responsiveness.

\begin{tabular}{|c|c|c|c|c|c|}
\hline & $n$ & $\begin{array}{l}\text { Total response } \\
\text { (APs) }\end{array}$ & $\begin{array}{l}\text { Burst response } \\
\text { (APs) }\end{array}$ & $\begin{array}{l}\text { Plateau response } \\
\text { (APs) }\end{array}$ & $\begin{array}{l}\text { Discharge after stimulus } \\
\text { (APs) }\end{array}$ \\
\hline Control: all & 33 & $56.4 \pm 3.0$ & $28.2 \pm 1.2$ & $27.8 \pm 2.6$ & $2.2 \pm 0.3$ \\
\hline Vincristine: all & 39 & $83.3 \pm 6.5^{*}$ & $31.8 \pm 1.9$ & $51.3 \pm 5.4^{*}$ & $3.3 \pm 1.0$ \\
\hline Vincristine: low-firing & 23 & $52.9 \pm 3.3$ & $26.0 \pm 1.7$ & $26.3 \pm 2.8$ & $2.2 \pm 0.3$ \\
\hline Vincristine: high-firing & 16 & $127.1 \pm 4.5^{*}$ & $40.2 \pm 3.1^{*}$ & $87.3 \pm 3.9^{*}$ & $5.0 \pm 2.4$ \\
\hline
\end{tabular}

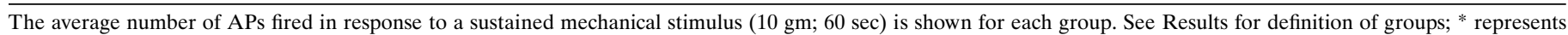
$p<0.01$ compared to the mean response of control C-fiber nociceptors. 


\section{Mechanical responsiveness}

\section{Heat responsiveness}

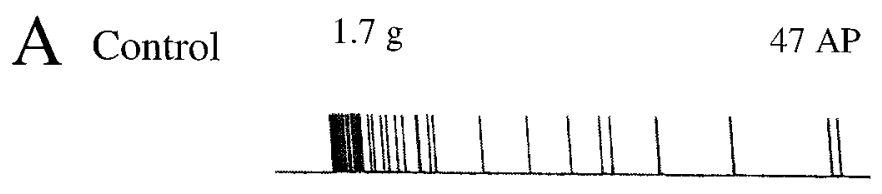

$40.4^{\circ} \mathrm{C}$

$55 \mathrm{AP}$
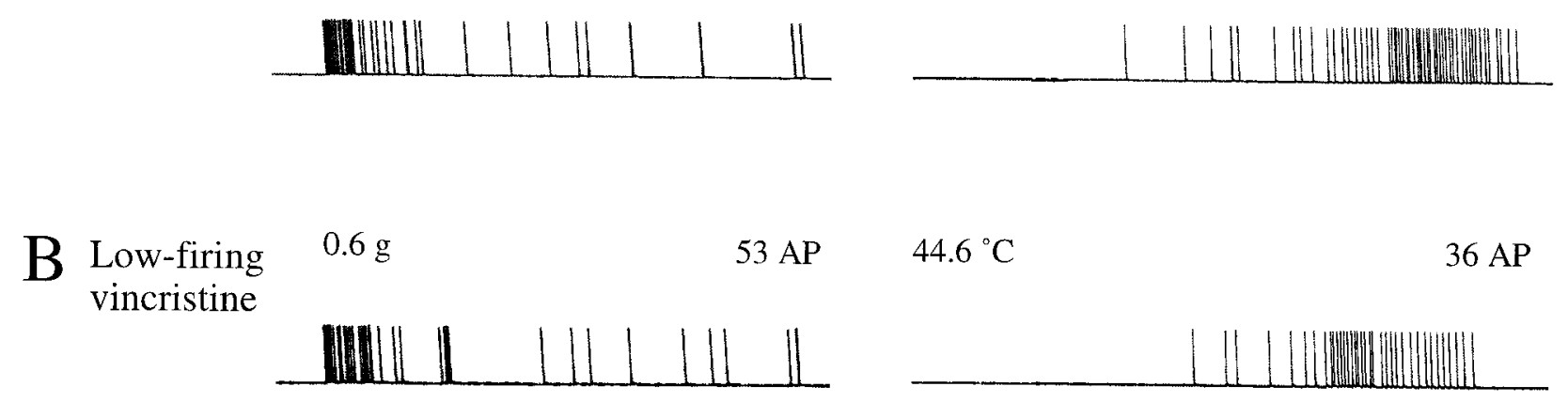

$44.6^{\circ} \mathrm{C}$

$36 \mathrm{AP}$
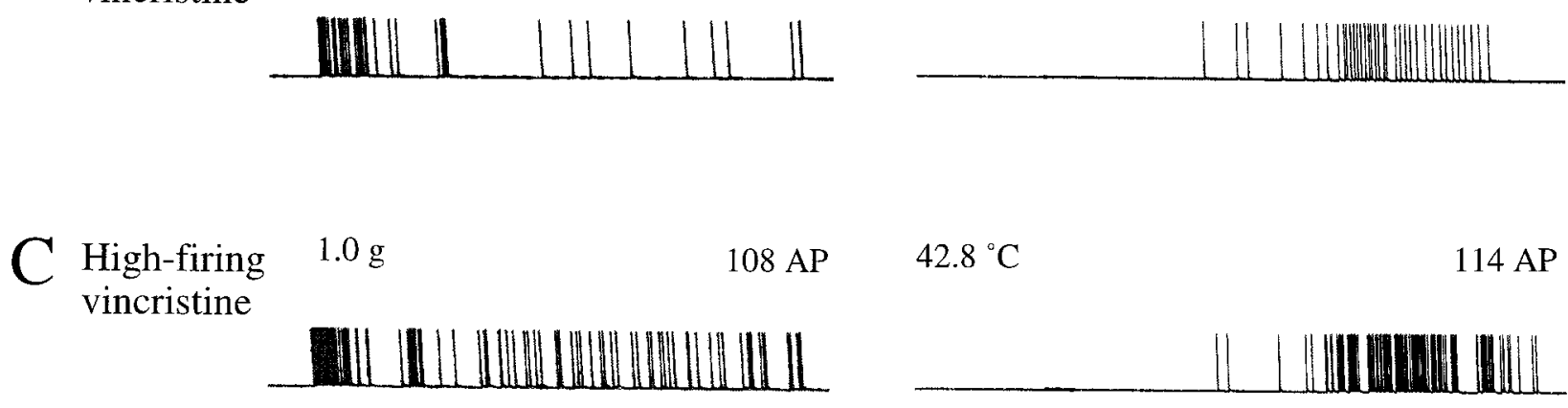

$42.8^{\circ} \mathrm{C}$

$114 \mathrm{AP}$
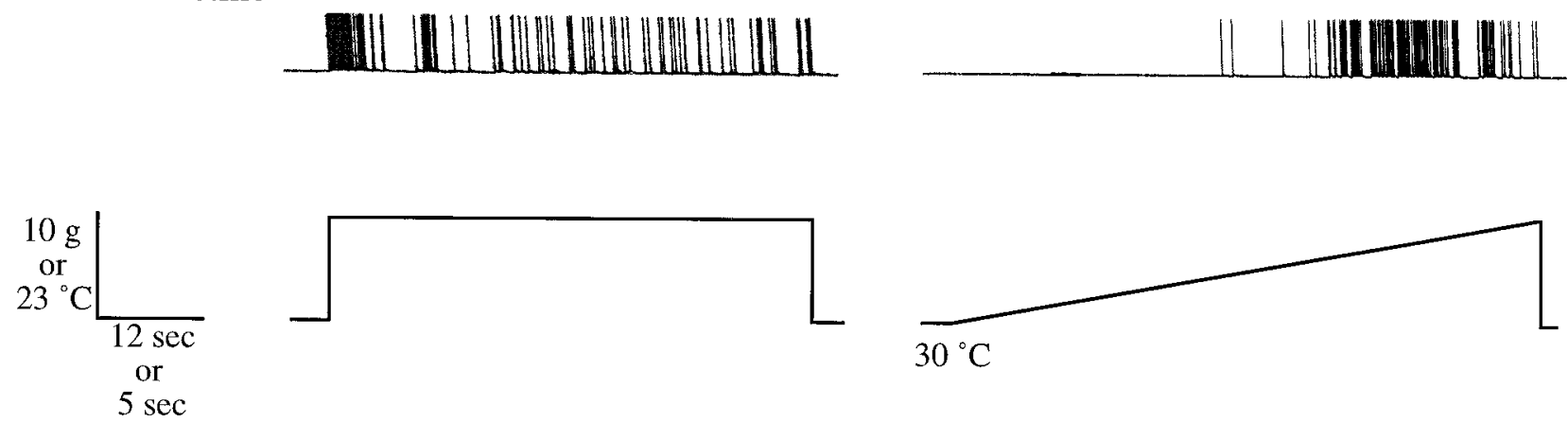

$30{ }^{\circ} \mathrm{C}$

Figure 7. Vincristine causes heat hyper-responsiveness in high-firing vincristine-treated nociceptors. Example responses to mechanical stimulation (1 min; $10 \mathrm{gm}$ ) and heat stimulation (ramp from 30 to $53^{\circ} \mathrm{C}$ at $1^{\circ} \mathrm{C} / \mathrm{sec}$ ) for a $\mathrm{C}$-fiber from a control rat with a mechanical threshold of $1.7 \mathrm{gm}$ and a heat threshold of $40.4^{\circ} \mathrm{C}(A)$, a low-firing $\mathrm{C}$-fiber from a vincristine-treated rat with a mechanical threshold of $0.6 \mathrm{gm}$ and a heat threshold of $44.6^{\circ} \mathrm{C}(B)$, and a high-firing C-fiber from a vincristine-treated rat with a mechanical threshold of $1.0 \mathrm{gm}$ and a heat threshold of $42.8^{\circ} \mathrm{C}(C)$. The number of APs fired during each stimulation trial is shown in the upper right of each trial.

\section{Mechanisms of hyper-responsiveness to only mechanical stimulation}

Although vincristine-treated nociceptors can be hyper-responsive to both mechanical and heat stimulation, most mechanically hyper-responsive nociceptors studied did not exhibit detectable hyper-responsiveness to heat stimulation. There were no examples in our data of vincristine-treated nociceptors that exhibited heat hyper-responsiveness in the absence of mechanical hyperresponsiveness. These data suggest that vincristine may affect mechanisms of mechanotransduction without affecting general mechanisms of nociceptor responsiveness.

Hyper-responsiveness to only mechanical stimulation could occur because of alterations in axonal transport, perhaps stranding dysfunctional proteins involved in mechanotransduction. This would require that proteins involved in mechanotransduction degrade, are transported, and/or are replenished on a different timescale than are those involved in heat transduction. For axotomized C-fiber afferents, the neuroma tip of the axon develops both novel heat and mechanical sensitivity on approximately the same timescale, within hours of transection (Michaelis et al., 1995; Blenk et al., 1996).

More likely, modality-specific hyper-responsiveness might result from direct effects of vincristine on the mechanotransduction apparatus. Cytoskeletal disorganization and microtubule disorientation occur in unmyelinated axons when nociceptors are hyperresponsive (Tanner et al., 1998) and might also occur in nociceptive nerve terminals. Although the mechanisms of mechanical transduction are unknown in vertebrate somatic afferents, a role for cytoskeletal elements has been postulated (Guharay and Sachs, 1984; Wang et al., 1993). In Caenorhabditis elegans, sensory neurons required for mechanosensation express a unique class of microtubules that are required for touch sensitivity (Chalfie, 1993). In addition, these touch cells express sodium channels that share homology with epithelial sodium channels found in the kidney that are thought to be involved in osmotic regulation (Chalfie, 1993; Canessa et al., 1994). Interestingly, the function of these putative sodium channel osmo- or mechanotransducers can be regulated by the cytoskeleton (Berdiev et al., 1996). 
A

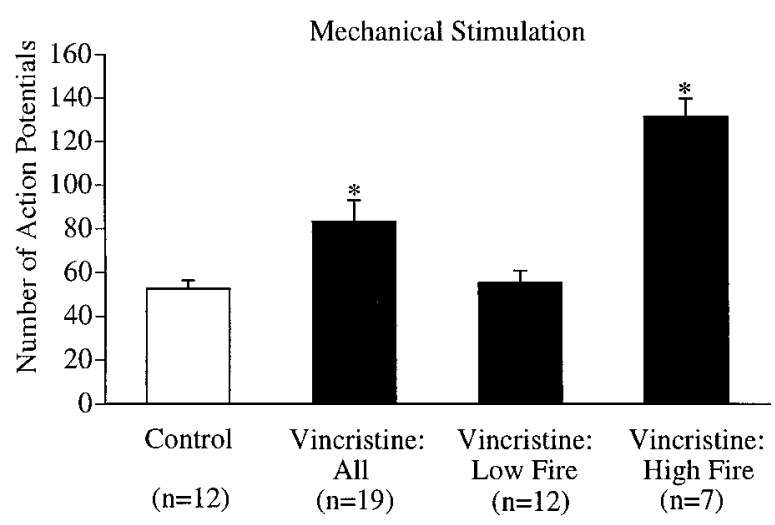

B

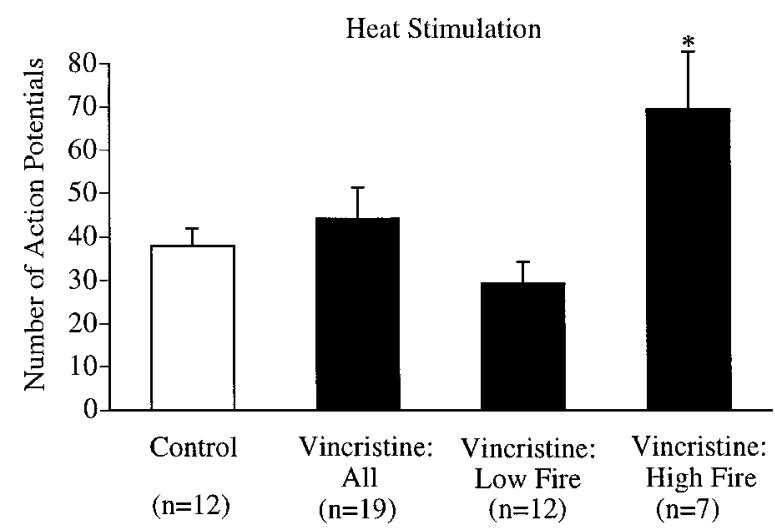

Figure 8. Heat hyper-responsiveness occurs in high-firing but not in low-firing vincristine-treated nociceptors. $A$, The average response to mechanical stimulation (10 gm; $1 \mathrm{~min})$ for control C-fibers studied with both heat and mechanical stimulation $(n=12)$ is shown in the open bar. For vincristine-treated C-fibers studied with both heat and mechanical stimulation, the average response to mechanical stimulation is shown in the filled bars for all vincristine-treated $\mathrm{C}$-fibers $(n=19)$, for low-firing vincristine-treated C-fibers $(n=12)$, and for high-firing vincristine-treated $\mathrm{C}$-fibers $(n=7)$. $B$, The average response to heat stimulation (ramp from 30 to $53^{\circ} \mathrm{C}$ at $1^{\circ} \mathrm{C} / \mathrm{sec}$ ) for control C-fibers studied $(n=12)$ is shown in the open bar. The average response to heat stimulation for all vincristine-treated $\mathrm{C}$-fibers studied $(n=19)$, for low-firing vincristine-treated C-fibers $(n=12)$, and for high-firing vincristine-treated C-fibers $(n=7)$ is shown in the filled bars. ${ }^{*} p<0.05$ or less.

\section{C-fiber dysfunction in vincristine-induced neuropathy is distinct from that seen in inflammation}

The profile of changes seen in vincristine-treated C-fibers is markedly different from the profile seen after inflammation or the administration of a single inflammatory mediator. After inflammatory insults, C-fibers characteristically have lower activation thresholds, as well as increased responsiveness to a sustained stimulus. In contrast, the mechanical activation thresholds of vincristine-treated $\mathrm{C}$-fibers are not lowered. This suggests that the cellular mechanisms that underlie $\mathrm{C}$-fiber nociceptor sensitization after inflammation may be distinct from those underlying C-fiber dysfunction observed in neuropathy. Furthermore, the dissociation between changes in activation threshold and changes in stimulus-response properties suggests that these neuronal properties can be independently regulated and might have distinct underlying molecular mechanisms.
A

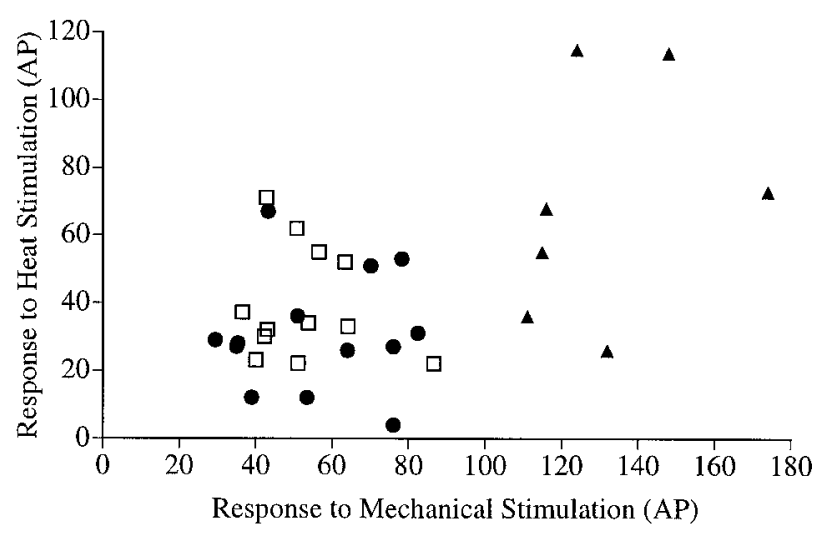

$\mathrm{B}$

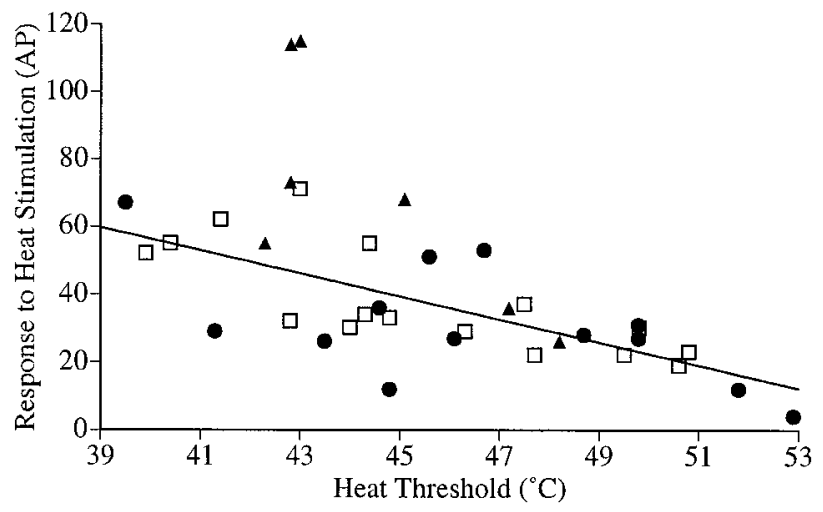

Figure 9. Heat hyper-responsiveness occurs in some, but not all, highfiring vincristine-treated nociceptors. $A$, The response to mechanical stimulation for control $\mathrm{C}$-fibers plotted against the response to heat stimulation of that nociceptor for control C-fibers $(n=12 ; \square)$, for low-firing vincristine-treated C-fibers $(n=12$; $)$, and for high-firing vincristine-treated $\mathrm{C}$-fibers $(n=7 ; \mathbf{\Delta})$. $B$, The response to heat stimulation plotted against the heat threshold of that nociceptor for control C-fibers $(n=16 ; \square)$, for low-firing vincristine-treated C-fibers $(n=12$; $\boldsymbol{0})$, and for high-firing vincristine-treated C-fibers $(n=7$; $\mathbf{\Delta})$. The regression line for control data is shown for reference.

\section{Nociceptor hyper-responsiveness in other models of neuropathic pain}

Interestingly, in other neuropathic pain models in which the transduction properties of nociceptors have been studied, hyper-responsiveness to heat or mechanical stimulation is seen. In diabetic neuropathy, mechanical hyper-responsiveness is observed, but heat responsiveness has not been examined (Ahlgren et al., 1992; Ahlgren and Levine, 1994). It is not known whether mechanical hyper-responsiveness is a feature of other neuropathy models such as the chronic constriction injury model (Bennett and Xie, 1988) or the partial nerve transection model (Seltzer et al., 1990), although there is preliminary evidence of heat hyper-responsiveness of C-fibers in the former (Koltzenburg et al., 1994). Our data suggest that both heat and mechanical hyper-responsiveness can occur during vincristine-induced neuropathy. In each of these models, heat or mechanical hyper-responsiveness occurs in the absence of a reduction in heat or mechanical activation thresholds, and a subset of $\mathrm{C}$-fibers exhibit pronounced afterdischarges after removal of the stimulus (Ahlgren et al., 1992; Koltzenburg et al., 1994). Taken together, these studies are compatible with 
A

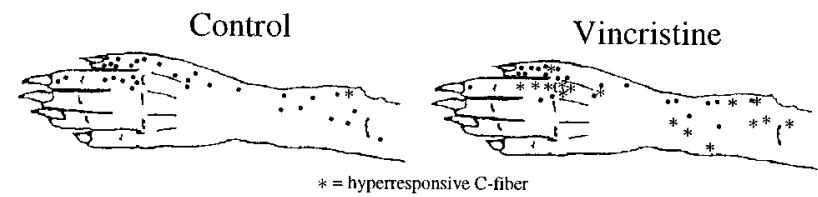

B

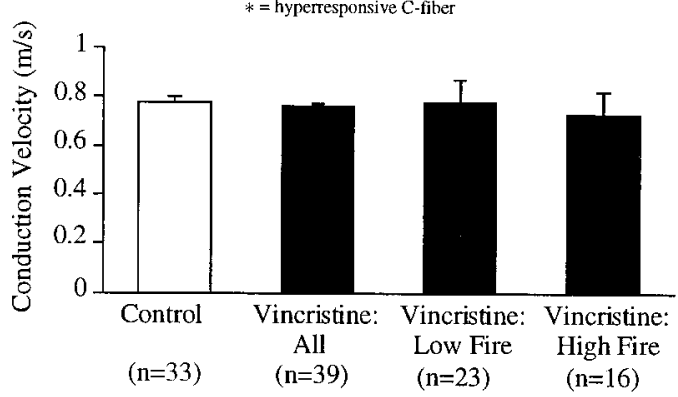

$\mathrm{C}$

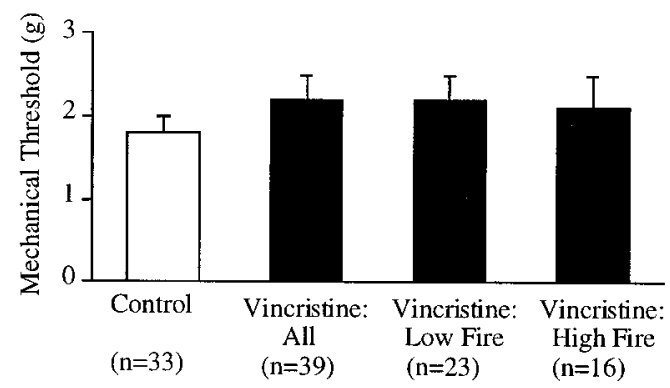

$\mathrm{D}$

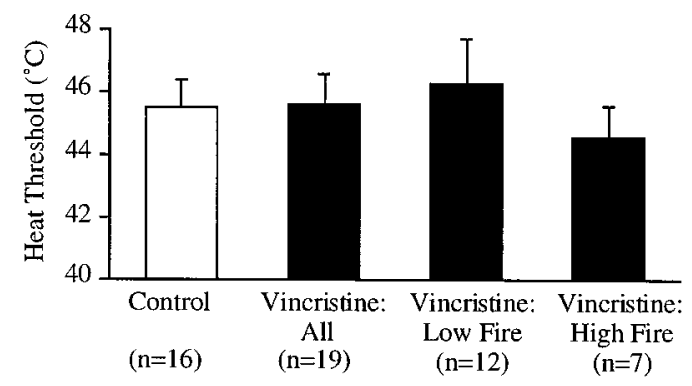

Figure 10. Mechanical hyper-responsiveness in nociceptors is not correlated with receptive field location, conduction velocity, or mechanical or heat threshold. $A$, The receptive field locations for all $\mathrm{C}$-fibers studied are shown for control C-fibers (left) and for vincristine-treated C-fibers (right). Low-firing nociceptors are represented by $\mathbf{O}$, and high-firing, mechanically hyper-responsive nociceptors are represented by *. In this drawing of the left hindpaw, top is medial, and bottom is lateral. $B$, The average conduction velocity for control C-fibers studied $(n=33)$ is shown in the open bar. The average conduction velocity for all vincristine-treated C-fibers studied $(n=$ $39)$, for low-firing vincristine-treated C-fibers $(n=23)$, and for highfiring vincristine-treated C-fibers $(n=16)$ is shown in the filled bars. $C$, The average mechanical threshold for all control $\mathrm{C}$-fibers studied $(n=33)$ is shown in the open bar. The average mechanical threshold for all vincristine-treated $\mathrm{C}$-fibers studied $(n=39)$, for low-firing vincristine-treated C-fibers $(n=23)$, and for high-firing vincristinetreated C-fibers $(n=16)$ is shown in the filled bars. $D$, The average heat threshold for all control C-fibers studied $(n=12)$ is shown in the open bar. The average heat threshold for all vincristine-treated C-fibers studied $(n=19)$, for low-firing vincristine-treated C-fibers $(n=12)$, and for high-firing vincristine-treated C-fibers $(n=7)$ is shown in the filled bars. There are no significant differences between the groups.

the suggestion that common peripheral mechanisms of nociceptor hyper-responsiveness may exist for multiple classes of peripheral neuropathy (toxic, traumatic, and metabolic). If this is so, then the underlying pathophysiology of peripheral nerve injury could be mechanistically dissected.
Role of C-fiber hyper-responsiveness in vincristineinduced hyperalgesia and neuropathy

The hyper-responsive subpopulation of C-fibers that we have described could, in part, be the neural basis of vincristine-induced hyperalgesia in the rat and early stage vincristine-induced painful neuropathy in humans. These hyper-responsive C-fibers could directly contribute to hyperalgesia by increasing nociceptive afferent input to the CNS. Increased afferent input has been shown to increase the responsiveness of spinal cord dorsal horn neurons that could also contribute to the behavioral hyperalgesia (for review, see Woolf and Doubell, 1994). In addition, hyperresponsive $\mathrm{C}$-fibers could make a greater contribution to the behavioral reflex indirectly if the gain of their input to the spinal cord were potentiated by virtue of their hyperexcitability; thus, even though only $41 \%$ of vincristine-treated C-fibers are hyperresponsive, they might more effectively activate dorsal horn neurons and predominantly drive the behavioral reflex.

In conclusion, we have shown that nociceptor responsiveness was profoundly enhanced during the peak phase of vincristineinduced hyperalgesia in the rat. Vincristine treatment can cause nociceptors to be hyper-responsive to both heat and mechanical stimulation or to only mechanical stimulation. Thus, vincristineinduced nociceptor hyper-responsiveness might involve alterations in general cellular mechanisms that underlie nociceptor responses to multiple stimulus modalities or might also specifically alter mechanical responsiveness. These multiple mechanisms might contribute to behavioral mechanical hyperalgesia observed in rats treated with vincristine, as well as paresthesias and dysesthesias experienced by patients receiving vincristine as a chemotherapeutic agent.

\section{REFERENCES}

Ahlgren SC, Levine JD (1994) Protein kinase C inhibitors decrease hyperalgesia and $\mathrm{C}$-fiber hyperexcitability in the streptozotocindiabetic rat. J Neurophysiol 72:684-692.

Ahlgren SC, White DM, Levine JD (1992) Increased responsiveness of sensory neurons in the saphenous nerve of the streptozotocin-diabetic rat. J Neurophysiol 68:2077-2085.

Ahmad FJ, Baas PW (1993) Microtubules released from the neuronal centrosome are transported into the axon. J Cell Sci 108:2761-2792.

Aley KO, Reichling DB, Levine JD (1996) Vincristine hyperalgesia in the rat: a model of painful vincristine neuropathy in humans. Neuroscience 73:259-265.

Allan V, Vale R, Navone F (1991) Microtubule-based organelle transport in neurons. In: The neuronal cytoskeleton (Burgoyne R, ed) pp 257-282. New York: Wiley-Liss.

Bennett GJ, Xie YK (1988) A peripheral mononeuropathy in rat that produces disorders of pain sensation like those seen in man. Pain 33:87-107.

Berdiev BK, Prat AG, Cantiello HF, Ausiello DA, Fuller CM, Jovov B, Benos DJ, Ismailov II (1996) Regulation of epithelial sodium channels by short actin filaments. J Biol Chem 271:17704-17710.

Bigot D, Hunt SP (1990) Effect of excitatory amino acids on microtubule-associated proteins in cultured cortical and spinal neurones. Neurosci Lett 111:275-280.

Binet S, Chaineau E, Fellous A, Lataste H, Krikorian A, Couzinier JP, Meininger V (1990) Immunofluorescence study of the action of navelbine, vincristine, and vinblastine on mitotic and axonal microtubules. Int J Cancer 46:262-266.

Blenk KH, Michaelis M, Vogel C, Janig W (1996) Thermosensitivity of acutely axotomized sensory nerve fibers. J Neurophysiol 76:743-752.

Bradley WG, Lassman LP, Pearce GW, Walton JN (1970) The neuromyopathy of vincristine in man. Clinical, electrophysiological and pathological studies. J Neurol Sci 10:107-131.

Canessa CM, Schild L, Buell G, Thorens B, Gautschi I, Horisberger JD, Rossier BC (1994) Amiloride-sensitive epithelial $\mathrm{Na}^{+}$channel is made of three homologous subunits. Nature 367:463-467. 
Casey EB, Jellife AM, Le QP, Millett YL (1973) Vincristine neuropathy. Clinical and electrophysiological observations. Brain 96:69-86.

Castle MC, Margileth DA, Oliverio VT (1976) Distribution and excretion of $\left({ }^{3} \mathrm{H}\right)$ vincristine in the rat and the dog. Cancer Res 36:3684-3689.

Chalfie M (1993) Touch receptor development and function in Caenorhabditis elegans. J Neurobiol 24:1433-1441.

Cleveland DW, Hoffman PN (1991) Slow axonal transport models come full circle: evidence that microtubule sliding mediates axon elongation and tubulin transport. Cell 67:453-456.

Devor M (1994) The pathophysiology of damaged peripheral nerves. In: Textbook of pain (Wall PD, Melzack R, eds), pp 79-100. Edinburgh: Churchill Livingstone.

Devor M, Govrin LR, Angelides K (1993) $\mathrm{Na}^{+}$channel immunolocalization in peripheral mammalian axons and changes following nerve injury and neuroma formation. Brain Res 630:283-288.

Greig NH, Soncrant TT, Shetty HU, Momma S, Smith QR, Rapoport SI (1990) Brain uptake and anticancer activities of vincristine and vinblastine are restricted by their low cerebrovascular permeability and binding to plasma constituents in rat. Cancer Chemother Pharmacol 26:263-268.

Guharay F, Sachs F (1984) Stretch-activated single ion channel currents in tissue-cultured embryonic chick skeletal muscle. J Physiol (Lond) 352:685-701.

Himes RH, Kersey RN, Heller BI, Samson FE (1976) Action of the vinca alkaloids vincristine, vinblastine, and desacetyl vinblastine amide on microtubules in vitro. Cancer Res 36:3798-3802.

Hirokawa N (1993) Axonal transport and the cytoskeleton. Curr Opin Neurobiol 3:724-731.

Holland JF, Scharlau C, Gailani S, Krant MJ, Olson KB, Horton J, Shnider BI, Lynch JJ, Owens A, Carbone PP, Colsky J, Grob D, Miller SP, Hall TC (1973) Vincristine treatment of advanced cancer: a cooperative study of 392 cases. Cancer Res 33:1258-1264.

Kajander KC, Bennett GJ (1992) Onset of a painful peripheral neuropathy in rat: a partial and differential deafferentation and spontaneous discharge in A beta and A delta primary afferent neurons. J Neurophysiol 68:734-744.

Kaplan RS, Wiernik PH (1982) Neurotoxicity of antineoplastic drugs. Semin Oncol 9:103-130.

Kirsch J, Langosch D, Prior P, Littauer UZ, Schmitt B, Betz H (1991) The $93 \mathrm{kDa}$ glycine receptor-associated protein binds to tubulin. J Biol Chem 266:22242-22245.

Koltzenburg M, Kees S, Budweiser S, Ochs G, Toyka K (1994) The properties of unmyelinated nociceptive afferents change in a painful chronic constriction neuropathy. In: Proceedings of the 7th World Congress on Pain (Gebhart G, Hammond D, Jensen T, eds), pp 511522. Seattle: International Association for the Study of Pain.

McCarthy GM, Skillings JR (1992) Jaw and other orofacial pain in patients receiving vincristine for the treatment of cancer. Oral Surg Oral Med Oral Pathol 74:299-304.
McLeod JG, Penny R (1969) Vincristine neuropathy: an electrophysiological and histological study. J Neurol Neurosurg Psychiatry 32:297-304.

Michaelis M, Blenk KH, Janig W, Vogel C (1995) Development of spontaneous activity and mechanosensitivity in axotomized afferent nerve fibers during the first hours after nerve transection in rats. J Neurophysiol 74:1020-1027.

Olmsted JB, Borisy GG (1973) Microtubules. Annu Rev Biochem 42:507-540.

Owellen RJ, Hartke CA, Dickerson RM, Hains FO (1976) Inhibition of tubulin-microtubule polymerization by drugs of the vinca alkaloid class. Cancer Res 36:1499-1502.

Rosenmund C, Westbrook GL (1993) Calcium-induced actin depolymerization reduces NMDA channel activity. Neuron 10:805-814.

Sandler SG, Tobin W, Henderson ES (1969) Vincristine-induced neuropathy. A clinical study of fifty leukemic patients. Neurology 19:367-374.

Seltzer Z, Dubner R, Shir Y (1990) A novel behavioral model of neuropathic pain disorders produced in rats by partial sciatic nerve injury. Pain 43:205-218.

Sheetz MP, Martenson CH (1991) Axonal transport: beyond kinesin and cytoplasmic dynein. Curr Opin Neurobiol 1:393-398.

Sheetz MP, Steuer ER, Schroer TA (1989) The mechanism and regulation of fast axonal transport. Trends Neurosci. 12:474-478.

Shelanski ML, Wisniewski H (1969) Neurofibrillary degeneration induced by vincristine therapy. Arch Neurol 20:199-206.

Srinivasan Y, Elmer L, Davis J, Bennett V, Angelides K (1988) Ankyrin and spectrin associate with voltage-dependent sodium channels in brain. Nature 333:177-180.

Tanner K, Levine J, Topp K (1998) Microtubule disorientation and axonal swelling in unmyelinated sensory axons during vincristineinduced painful neuropathy in rat. J Comp Neurol 395:481-492.

Wall PD, Gutnick M (1974) Ongoing activity in peripheral nerves: the physiology and pharmacology of impulses originating from a neuroma. Exp Neurol 43:580-593.

Wang N, Butler JP, Ingber DE (1993) Mechanotransduction across the cell surface and through the cytoskeleton. Science 260:1124-1127.

Weiss HD, Walker MD, Wiernik PH (1974) Neurotoxicity of commonly used antineoplastic agents (second of two parts). N Engl J Med 291:127-133.

Woolf CJ, Doubell TP (1994) The pathophysiology of chronic painincreased sensitivity to low threshold A beta-fibre inputs. Curr Opin Neurobiol 4:525-534.

Xie YK, Xiao WH (1990) Electrophysiological evidence for hyperalgesia in the peripheral neuropathy. Sci China [b] 33:663-672.

Zhou XJ, Martin M, Placidi M, Cano JP, Rahmani R (1990) In vivo and in vitro pharmacokinetics and metabolism of vincaalkaloids in rat. II. Vinblastine and vincristine. Eur J Drug Metab Pharmacokinet $15: 323-332$. 